CHRISTIAN C. CÁCERES SANDOVAL

(Universidad Nacional Mayor de San Marcos)

\title{
LAS ESTRATEGIAS TEXTUALES EN LA CRÍTICA DE LA ADMINISTACIÓN Colonial en la Historia General del PERÚ DE Fray MARTín DE MURÚA
}

\section{Textual Strategies in the Criticism of the Colonial Administration in the General history of Peru by friar Martín de Murúa}

\begin{abstract}
This article intends to provide a new approach to the discursive mechanisms of the General History of Peru by Friar Martín de Murúa, shedding light on his work. We will show how he slips a clear criticism of the colonial order from which he writes resorting to the exemplary tradition and also how he sets a model for the administration. On the other hand, we must notice that the censorship existing at the time produces a convoluted text, with a carefully weaved argumentative web that plays on several topics by reworking them to the author's benefit.
\end{abstract}

KEY WoRDS: Exemplary tradition, Peruvian colonial historiography, Post-Toledan chroniclers, Martín de Murúa, General history of Perú.

RESUMEN: Nuestro trabajo intenta una aproximación a los mecanismos argumentativos de la Historia general del Perú de fray Martín de Murúa y sumar así nuevas luces en torno a la obra del mercedario. Demostraremos cómo este desliza una decidida crítica al orden colonial desde el que escribe recurriendo a la tradición ejemplar y cómo, además, plantea un arquetipo de administración. Por otro lado, debemos advertir que la censura de la época provoca un texto sinuoso, una cuidadosa red argumentativa que juega a su vez con algunos tópicos reelaborándolos para su beneficio.

Palabras Clave: Tradición ejemplar, historiografía colonial peruana, cronistas postoledanos, Martín de Murúa, Historia general del Perú.

Fecha de Recepción: 25 de octubre de 2020.

Fecha de Aceptación: 14 de diciembre de 2020.

\section{Introducción}

ESCASOS Y POCO PROBABLES, EN SU MAYORÍA, SON LOS DATOS QUE conocemos acerca del autor de la crónica que nos ocupa. Es más, el propio Murúa es quien consigna la mayor parte de ellos en dicho texto. Tanto el lugar de su nacimiento (Guipúzcoa) como la fecha del mismo (entre 1525 y 1535), la de su ordenamiento como mercedario (antes de los 25 años) y la de su paso a territorio peruano confirman la ya señalada incertidumbre. Mayor luz existe sobre su estancia en la tierra de los incas: comendador del convento de Huerta, cura doctrinero en Capachica, cura de Huata, vicario de Aymaraes y comendador de Yanaoca. ${ }^{1}$

1 Para mayores detalles remitimos a la enjundiosa introducción de Ballesteros Gaibrois (2001) a la crónica del mercedario. Ahora bien, es necesario indicar que la reciente investigación de Aguinagalde 
Hasta hace relativamente poco el mismo panorama se cernía en torno a su obra; sin embargo, en el transcurso de los años se ha despejado nuestro conocimiento sobre la misma, no así la atención por parte de los críticos. Este desinterés obedece, en primer lugar, a su tardío descubrimiento: desde 1922 se sabe de su existencia gracias a una edición a cargo de Horacio H. Urteaga y D. Carlos A. Romero; en 1946 Raúl Porras Barrenechea publica en Lima una segunda edición y, ese mismo año, Constantino Bayle publica en Madrid la suya. Cabe señalar que todas ellas eran versiones fragmentadas de una copia de la primera versión de la crónica de Murúa, el manuscrito Loyola. Copia que luego desapareció y que fue el origen de las evidentes ausencias y divergencias de dichas publicaciones. Lo paradójico es que hasta ese momento no se sospechaba de la existencia de una primera versión como tal. Cuando fija su edición, el mismo Ballesteros (2001: 13) sostiene que el manuscrito Loyola sea quizá la copia de borradores o «en sí mismo un sucio anterior del original». ${ }^{2}$ Es justamente este investigador quien logra descubrir la versión final del texto de Murúa, el manuscrito Wellington, hacia 1950, y la publica entre 1962 y 1964 en una reducida tirada de solo 500 ejemplares. Habría que esperar hasta 1987 para una reedición más amplia y dirigida a un público menos especializado; otra reedición, de similares características, apareció el 2001.

La segunda razón, no menos importante, es el lugar que ocupa en la tradicional periodización de las crónicas peruanas: Murúa se encuentra dentro de los llamados cronistas postoledanos, es decir, flanqueado (y oscurecido) por las figuras de Felipe Guaman Poma de Ayala y del Inca Garcilaso de la Vega. ${ }^{3}$ Como es evidente, la atención de los especialistas ha recaído sobre estos últimos en detrimento del cronista vasco (igual situación comparte su coetáneo Miguel Cabello de Balboa). Finalmente, cabe señalar que las famosas y furibundas denuncias de Guaman Poma hacia nuestro cronista han despertado, de alguna manera, cierto interés de los estudiosos y han dado pie a algunos trabajos sobre el particular.

En consecuencia con este último punto, esta desatención ha provocado que la literatura crítica sobre la Historia general del Perú no se caracterice, precisamente, por su

(2019) dibuja un panorama completamente distinto: sostiene que Murúa nació en Escoriatza el uno de noviembre de 1566 y que falleció el seis de diciembre de 1615 en la misma localidad. Aunque su argumentación es bastante sólida, nosotros compartimos los reparos de Ossio y Cummins (2019): resulta improbable que Murúa, con poco más de veinte años, sea capaz de acometer una empresa que entraña ciertas dificultades y exige no pocos conocimientos; por ejemplo, algo más que rudimentos del quechua, cierta familiaridad con la tradición historiográfica y con la población andina, etc.

2 Como sabemos ahora, aquel sucio original resultó ser el manuscrito Galvin, la primera versión de la obra del fraile vasco, descubierto tras una ardua investigación por Juan Ossio en 1996 y dada a las imprentas en edición facsimilar ocho años después. Nosotros, sin embargo, analizaremos la versión final.

3 Para una detallada información sobre estos cronistas y sus características véase García Bedoya (2000). Asimismo, para una expeditiva síntesis sobre las diversas clasificaciones en torno a los cronistas de la región andina puede consultarse Pease (1995: 111). 
abundancia. Ahora bien, si se echa un rápido vistazo sobre esta se observará que gran parte de ella explora su dimensión intertextual: Porras Barrenechea (1986), Rowe (1987) y Álvarez-Calderón (2007) han demostrado cómo nuestro cronista se apropia casi textualmente de materiales ajenos. Desde perspectivas diferentes, los trabajos de Adorno (2004) y de Adorno y Boserup (2008) constituyen otros aportes significativos; en el primero de ellos se revela el rol de la censura y, sobre todo, la del material censurado en la crónica en cuestión, mientras que el segundo detalla con minuciosidad las relaciones entre la primera y la última versión de la obra de Murúa.

En este contexto, nuestro trabajo se centra en el texto mismo y busca evaluar sus mecanismos de significación; de esta manera, pretendemos esclarecer algunos aspectos en los que la mencionada literatura crítica no ha reparado. Básicamente, buscamos demostrar que la Historia general del Perú tiene una fuerte dimensión crítica que, para escapar de la censura, ${ }^{4}$ echa mano de diversas tradiciones, en especial, la ejemplar. El blanco de sus cuestionamientos es la deficiente administración colonial de su tiempo, ineficacia que reside, para Murúa, en la extrema codicia de sus funcionarios. En este sentido, no se trata de una crítica del sistema sino de sus ejecutantes. Ello explica por qué nuestro mercedario deja entrever a ratos (los más) tibios cuestionamientos al orden colonial existente; a ratos (los menos), encendidos elogios: esta actitud contradictoria se torna aparente a la luz de esta distinción. Sin embargo, esto no impide que nuestro cronista denuncie el dramático descenso de la población indígena como otro efecto de la impericia colonial, ineficacia que se resalta al compararse con los dos modelos que propone de manera implícita Murúa: el gobierno incaico y la labor del virrey don Francisco de Toledo (1569-1581).

1.

Antes de iniciar el análisis es necesario realizar una sucinta descripción de la crónica en cuestión, que tiene dos partes básicas: una importante sección paratextual ${ }^{5}$ denominada "Al lector" (cabe anotar que Murúa lo acompaña de trece recomendaciones/validaciones sobre la obra) y el texto en sí mismo. Este último se encuentra dividido en tres libros. El primero, compuesto por noventa y tres capítulos, atañe a la historia del Tahuantinsuyo. Se ensaya una biografía de cada inca con su correspondiente coya (desde Manco Cápac hasta la ejecución de Túpac Amaru I) y se narran sus principales hechos; las únicas excepciones están

${ }^{4}$ Ya Friede (1959) advirtió su importancia en el circuito cultural hispanoamericano colonial. La obra del mercedario no es ajena a ella y su presencia va a determinar, en cierto modo, su escritura. Para un análisis detallado sobre su efecto véase Adorno (2004).

5 Genette (1989: 11-12) define así a todo elemento que no forme parte del cuerpo textual mismo, sino que lo rodea. Acompaña al texto, lo presenta: portadas, títulos, subtítulos, dedicatorias, epígrafes, prólogos, notas a pie de página, etc. Para un análisis exhaustivo de dichos elementos, consúltese Genette (2001). 
constituidas por el primer capítulo que aborda la etapa preincaica y los ocho capítulos finales dedicados a anécdotas memorables (o bien de los soberanos o bien de otros personajes importantes del incanato). El segundo libro, compuesto por cuarenta capítulos, informa y describe tres aspectos del Tahuantinsuyo. En primer lugar sobre el inca y sus costumbres; en segundo, sobre su gobierno: la administración y las tradiciones impuestas; y, en tercer lugar, sobre la dimensión religiosa del incario. Finalmente, el tercer libro, compuesto de treinta y un capítulos, es una descripción que comprende el aspecto geográfico del territorio peruano, el régimen administrativo colonial, el plano eclesiástico (con énfasis especial en la orden mercedaria) y, finalmente, el recuento de las ciudades fundadas por los españoles en el Perú.

Esbozado el esquema general de la crónica, es fundamental revisar con minuciosidad el paratexto. La breve introducción (diez páginas) a la Historia general del Perú puede ser dividida en cuatro partes: ${ }^{6}$

(1) La introducción propiamente dicha, que consta de una breve página y en la que expone sucintamente las razones y los fines de su obra.

(2) Dos composiciones poéticas elogiando al cronista.

(3) La colección de una serie de autorizaciones o legitimaciones sobre la crónica y sobre su autor, trece en total (incluida la licencia de impresión), hecha por diversas personalidades del virreinato.

(4) Una presentación y dedicatoria dirigida al futuro rey Felipe IV.

Nosotros nos vamos a centrar en la introducción propiamente dicha. Aquí, Murúa comienza empleando una oración concesiva, mediante la cual se reconoce de entrada la existencia de un nutrido corpus de crónicas sobre el tema que va a abordar, tanto de manera general como particular: «Aunque muchos han tocado los sucesos de los Yncas [...] y aun algunos han hecho particulares libros» (27). Sin embargo, tras esta permissio, Murúa apela a la auctoritas, en este caso, para legitimar su discurso, recurre a una traducción de la definición de historia que Cicerón ofrece en De oratore 2.9.36: Historia vero testis temporum, lux veritatis, vita memoriae, magistra vitae, nuntia vetustatis:

si se ha de guardar el rigor de lo que quiere decir Historia, conforme la definió Cicerón en el libro $2^{\circ}$ de sus oraciones que dijo que la Historia era testigo de los Tiempos, Luz de la Verdad, Vida de la Memoria, Maestra de la Vida y Correo de la Antigüedad, ninguno pienso que ha cumplido con todas estas condicionales con el rigor que yo he deseado cumplir (27).

6 Remitimos en el estudio únicamente a las páginas de la edición de Ballesteros Gaibrois (Murúa, 2001). En adelante todas las citas serán de esta edición. 
Nótense aquí dos cosas: en primer lugar, la forma sutil como recubre de falsa modestia su intención, de aquí el empleo del condicional y el tono subjetivo que imprime a sus palabras. No se trata de una afirmación categórica, sino de posibles: si se ha de guardar, ninguno pienso, he deseado. En segundo lugar, y más importante, la posición de saber que asume el cronista, de aquí el recurso a Cicerón y la precisión de la cita. Murúa legitima su Historia general del Perú basándose en un saber hacer, en un cómo discurrir sobre el género historiográfico. En resumen, esta conciencia de letrado se suaviza bajo los ropajes de la falsa modestia.

Sin duda, estamos ante la «importancia de la armonía discursiva» (Mignolo, 1982: 93) que caracteriza a los cronistas de fines del siglo XVI: ya no se trata tanto de la verdad empírica, de la posesión de la historia sino más bien de la posesión del discurso, de las formas historiográficas exigidas: "“tener discurso" significa poner la relación en los términos exigidos por la formación discursiva» (Mignolo, 1982: 90). En resumen, esta declaración de principios no solo sirve para hacerse un lugar de privilegio y novedad entre la ya abundante producción realizada sobre el incario, sino que también explica los flagrantes "plagios" que se denuncian en la obra del mercedario. ${ }^{7}$ Para la época lo importante no radica en el qué sino en el cómo: es decir, saber dotar al texto de armonía y, en especial, de coherencia.

Inmediatamente después de afirmar este prurito de rigurosidad, Murúa busca demostrarlo siguiendo punto por punto la definición ciceroniana. En primer lugar, nuestro fraile vasco lo basa en la recolección y consulta de dos tipos de fuentes, orales y materiales ("escritos"), aparte de en su propia experiencia indiana. En cuanto a lo oral, señala: «he conferido lo que escribo con los testigos de entrambos tiempos» (27); esto responde a la primera sentencia de Cicerón, la historia como testigo de los tiempos (testis temporum). Cabe resaltar los criterios de selección de fuentes indígenas del mercedario: edad y entendimiento («indios de mayor edad y discurso», 27). En cuanto a lo "escrito", el mercedario afirma que estuvo «revolviendo su modo de archivos y depósitos más olvidados y sepultados» (27). De esta última labor, el cronista desprende la segunda y tercera definición de Cicerón (lux veritatis y vita memoriae): «con que se ha dado la luz posible a la verdad que se busca y vida a la memoria que se iba a acaban» (27). Nótese que los subrayados nuestros destacan dos cosas: (1) la falibilidad de lo escrito, no por culpa del cronista sino por la corrupción e inseguridad de las fuentes, y (2) la conciencia de la importancia de su labor (la crónica como un paliativo del olvido).

7 Por ejemplo, las acusaciones de plagiar a Guaman Poma de Ayala hechas por Porras Barrenechea (1986). De la misma manera, también Rowe (1987) subraya las "coincidencias" entre la obra de Gómara y la del mercedario. Finalmente, Álvarez-Calderón (2007) ofrece un abanico más amplio de textos tomados por Murúa: el Symbolo Catholico Indiano (1598) de Fr. Jerónimo de Oré, la República de Indias (1575 y 1595) de Fr. Jerónimo de Román y Zamora, Los Errores y Supersticiones de los indios y de la Instrucción contra las ceremonias y ritos... de Polo de Ondergardo y la Historia de los Incas de Sarmiento de Gamboa. Asimismo, la autora se encarga de reseñar otros estudios al respecto. 
Finalmente, en la penúltima definición de Cicerón (magistra vitae) se concentra la densidad explicativa: para las tres anteriores se emplearon seis líneas, la misma cantidad que para esta última. Dicha densidad es proporcional a la importancia de lo que se propondrá como objetivo de la narración histórica, configurarse como modelo de gobierno: «con la buena política que se verá en la descripción, que aquí ponemos de aquellas provincias [las peruanas] con que se ha seguido el último fin que se pretende en la historia, que es recreado enseñar a vivir a los que leen, con el ejemplo de los que pasaron» (27). Murúa deja claro desde el principio el talante perlocutivo de su escrito. Más adelante, veremos también como el de su interlocutor ideal.

El paratexto cierra con una serie de autorizaciones (catorce) y la licencia de impresión que va a consignar en las siguientes páginas. Deja el juicio de su obra al escrutinio atento de estos personajes: «todo lo uno y lo otro [los argumentos esgrimidos] remito y sujeto a la erudición de tantos hombres graves como hoy escriben» (27). Ahora bien, la selección de estos garantes sigue dos criterios: (1) su relativa jerarquía (por ejemplo, entre ellos tenemos al gobernador de Tucumán, Luis Quiñones) y (2) su amplia experiencia en tierras indianas. Este último rasgo es crucial pues denota competencia a la hora del juicio.

Ahora bien, otro paratexto que merece ser evaluado es la dedicatoria de la crónica. Murúa fija como interlocutores a la pareja heredera: el actual príncipe, futuro rey Felipe IV, y su consorte Isabel de Borbón. A pesar de obedecer a un tópico, aquí se destacan dos cosas: la forma como conceptúa su propia obra («traygo un don y un tesoro copioso», 36) y los rasgos que le atribuye y que le proporciona ese carácter privilegiado («la verdad de la antigüedad y de la grandeza de la novedad», 36). Es decir, lo veraz y lo novedoso de su crónica la constituyen como un presente nada despreciable. Sin embargo, lo que llama verdaderamente la atención es que Murúa dedique la crónica al heredero y no al rey, ¿tal vez, y a la manera de un espejo de príncipes, el mercedario está mirando al futuro: solo el nuevo rey podrá hacerse cargo de los fallos que nuestro cronista irá deslizando a ratos en su texto (y que ya analizaremos)? Recordemos que, según Mignolo (1982), la crónica debe escribirse con cierta doble finalidad: desde un punto de vista filosófico, la historia debe ocuparse de verdades particulares; y estas verdades, desde el punto de vista público, deben estar al servicio de la utilidad comunitaria. En este sentido, el carácter modélico de la crónica del mercedario, que pone énfasis en el aparato político y administrativo, ¿está orientado a buscar una respuesta promisoria en la realidad futura y así mostrar su utilidad? ¿Esa es la finalidad de las décadas de trabajo y redacción, del largo y penoso viaje de retorno emprendido? ¿Debido a ello es que su Historia general del Perú es un «pronóstico felicissimo» (36)? Estas preguntas intentarán ser respondidas a lo largo de nuestro trabajo. 
En resumen, en este paratexto introductorio, Murúa hace gala de un saber hacer historiográfico y sustenta la importancia y lo singular de su trabajo en el rigor aplicado a su elaboración. ${ }^{8}$ El rasero al que se ciñe es la frase ciceroniana ya citada. De esta, además, se desprende el carácter docente de su labor: la historia que narre será un espejo donde el presente ha de mirarse y ha de advertir los errores y los aciertos del pasado. Y, por tanto, respectivamente, saber evitarlos e imitarlos. Por último, la dedicatoria refuerza dicha intencionalidad, generar un cambio, llamar la atención sobre lo que acontecía en los territorios andinos.

2.

La dimensión ejemplar de nuestra crónica, que se presagia como fundamental desde el paratexto analizado, pasará a ser una realidad, sobre todo, en su primer libro, el propiamente histórico. La mayoría de exempla que encontremos se van a formar en torno a vicios y virtudes: estos van a tomar cuerpo en alguno de los personajes y el destino de los mismos marcará las consecuencias del vicio o de la virtud. Por lo general, dichos pasajes están marcados por un inicio de tono homilético en el cual se expone el pecado, su origen, su naturaleza y sus consecuencias. Terminado el exordio, se empieza con la narración en sí. Por último, en la peroratio se vuelve a advertir sobre los peligros de dicho pecado. Finalmente, cabe señalar que podemos encontrar estos exempla tanto jugando un rol central en el decurso de la historia (de hecho, su sucesión está regida por la expiación de algún pecado) como de manera aislada, es decir, sin ninguna consecuencia en los acontecimientos narrados.

Esta coalescencia de diversas tradiciones (lo ejemplar, la homilética y la historiografía) en nuestro texto exige realizar un rápido recorrido histórico sobre la evolución de sus relaciones. En específico, solo nos limitaremos a circunscribir la presencia del exemplum en estos discursos y detallar algunos rasgos específicos de la época que nos atañe. Otro intento escaparía a los objetivos de nuestro trabajo.

En la retórica de la Antigüedad, el exemplum formaba parte de la argumentatio. Su contenido y sus funciones eran, según Harto Trujillo (2011: 511), las palabras o acciones de un personaje importante y la búsqueda por adornar el discurso, enseñar y persuadir mediante el mismo. Estas características son las que permiten entender su ligazón a la historiografía clásica:

por su carácter didáctico y moralizante, por centrarse en temas bélicos y políticos, por su relación con la épica y la tragedia y por ser en gran medida autobiográfica, no es sino una colección de exempla y de relatos protagonizados por auctoritates reconocidas por todos (Harto Trujillo, 2011: 513)

8 Según Mignolo (1982), esta conciencia sobre la historia como una labor especializada y que requiere de ciertas competencias (un "saber hacer") responde a otra de las características fundamentales de la crónica de Indias. 
Ahora bien, ya desde los primeros años del cristianismo y durante la Edad Media, el exemplum será adaptado por la Iglesia debido a su potencial persuasivo. Obviamente, se trocarán las virtudes ensalzadas (otras se mantendrán) y los personajes que encarnan dichos rasgos. Gregorio Magno será quién establezca la esencialidad de este recurso para la predicación. Harto Trujillo (2011: 515) sintetiza esta presencia así:

En la Edad Media cambia, pues, el marco (que ahora son homilías orales), cambia la fuente (biblicas o inventadas), la finalidad (religiosa), pero se mantiene la esencia del exemplum como recurso retórico y estético utilizado para la persuasión [...]. Importa también el relato en sí (que debe captar la atención de un público poco culto) y la enseñanza moral. Desde luego, el fin moralizante es la razón de ser del exemplum medieval, que utilizará en mayor medida lo cotidiano y trivial, lo folklórico y maravilloso, considerado un buen método para entretener y convencer al auditorio.

Como observación final, cabe anotar que, tras la normativización del sermón durante los siglos XII y XIII, se compusieron numerosas artes praedicandi que van a ir conjuntando diversas tradiciones como la patrística, la retórica clásica y el debate escolástico. ${ }^{9}$ Paralelamente a estos tratados que servían como material auxiliar para el predicador y que muchas veces contenían una compilación de exempla, se confeccionó y divulgó una serie de repertorios de estos últimos, creando así un vasto archivo. ${ }^{10}$ De esta manera, el exemplum adquiría cierta independencia y prestigio: ya no solo lo vamos a encontrar como parte del sermón o en las crónicas, sino también en los llamados espejos de príncipes o en textos de naturaleza literaria. Se va a convertir en una especie de subgénero.

Por tanto, en el Renacimiento existía ya una amplia tradición respecto al exemplum. Este período aportará una nueva función: si durante el Medioevo, y gracias a la homilética, la finalidad era religiosa y moral, ahora esta va a convivir con «la propagación de personajes y virtudes del pasado, que servirán muy bien para crear un modelo de conducta en personajes destacados como los reyes» (Harto Trujillo, 2011: 515). Parecida intención la hemos advertido en el paratexto analizado. Otro rasgo importante de este periodo es la reaparición del exemplum en los tratados retóricos humanistas con las mismas características y funciones que en la retórica clásica: un contenido basado en comparaciones con referentes de la realidad y una finalidad

9 Para una visión detallada y profunda sobre la evolución de estos tratados en el Medioevo puede consultarse Alberte (2003). Para una visión más general sobre el exemplum en la Edad Media, cf. Battaglia Ricci (2003), Berlioz (1980, 1991), Berlioz \& Polo De Beaulieu (1998, 2000), Bremond, Le Goff \& Schmitt (1982), Delcorno (1989), Le Goff (1988), Ricklin (2006) o Tubach (1969), entre otros muchos.

${ }^{10}$ Harto Trujillo (2011) afirma que entre los siglos XIII y XIV pueden contabilizarse más de cuarenta y seis de estos repertorios. 
estética, didáctica y perlocutiva. Nuevamente ligado a la argumentatio (Harto Trujillo, 2011: 516-520). ${ }^{11}$

A grandes trazos este es el contexto cultural europeo e hispánico en torno al exemplum. Como hemos visto, su funcionalidad es clave y le permite moverse tanto en la esfera historiográfica como en la homilética. Así, durante el Renacimiento su papel será clave en estas dos tradiciones. Además, su ejercicio será constante y parte de la formación universitaria. Para completar este panorama no debemos perder de vista la dimensión histórica. El quiebre que suscitó la Reforma y las medidas tomadas por Roma tras el Concilio de Trento (1545-1563) van a tener como corolario una revitalización del afán evangelizador y, por tanto, la dimensión homilética volverá a tener un papel preponderante en la sociedad hispánica:

La oratoria sagrada, a través de sus sermones, se configura así con una múltiple faceta: la primera es la de instrumento para la dirección espiritual, ligado a una finalidad moralizante en base a la transmisión y divulgación de los valores del catolicismo frente al resto de expresiones [...]; la segunda, quizá consecuencia de la primera, como herramienta de culturización de un pueblo que sufre lo que fray Luis de Granada dio en llamar «pestilencial ignorancia». (Cerezo Soler, 2018: 412)

Ahora bien, teniendo en cuenta este horizonte, describamos el espacio colonial de fines del siglo XVI y, en específico, el virreinato peruano. La importancia de lo homilético en los territorios de ultramar es casi una marca de nacimiento: desde el inicio de la conquista, la evangelización fue un objetivo señero. La cruz, a diferencia de la espada, nunca se envainó. En cuanto al espacio andino, si bien los primeros años del virreinato peruano estuvieron jalonados por una serie de guerras intestinas e insurrecciones contra la autoridad real (1537-1554), una vez sofocadas continuó con más ardor la tarea evangélica: la fundación de conventos e iglesias, la creación de la Universidad de Lima en 1551 como respuesta a la necesidad de la formación clerical (sus facultades originarias fueron Teología y Artes), el interés en las lenguas vernáculas como medio de conversión (afán materializado en la creación de la cátedra de quechua en 1577 y en los diversos catecismos editados en dichas lenguas), etc. Para esta efervescencia, el Tercer Concilio Limense (1582-1583) significó el establecimiento de una política común y una normativización bajo el espíritu dictaminado en Trento. ${ }^{12}$

Adorno (1987) se ha encargado de dibujar la impronta de dicho concilio para el ámbito homilético. En primer lugar, destaca la publicación de la Doctrina christianay catecismo para instrucción de los indios y de las demás personas (1584), catecismo trilingüe

11 Para una visión más profunda sobre el exemplum en el Renacimiento, cf. los trabajos de Aragüés Aldaz (1993, 1999), Maslakov (1984), Lafond (1986).

12 Para examinar con profundidad dichas medidas puede consultarse López Lamerain (2011). 
(español, quechua y aimara) y del Tercero catecismo y exposición de la doctrina christiana por sermones (1585), catecismo y libro de doctrina explicada mediante sermones en edición bilingüe (quechua y español). Todos estos títulos bajo la anuencia y el impulso del citado concilio. Como hemos observado con anterioridad, el sermón era considerado un instrumento esencial para que la población se acercara a la iglesia. Trasegada a América esta confianza, solo cambia el énfasis y el público: ahora son los indios quienes deben ser atraídos a la verdadera fe y alejados de sus idolatrías.

El Tercero catecismo va a jugar un rol importante en el escenario peruano. En primer lugar, su prefacio es una refundición sobre cómo se han de componer sermones, teniendo en cuenta aspectos como: la conciencia del auditorio y, en consecuencia, la modulación de un lenguaje adecuado a este; un estilo coloquial; la repetición de argumentos con el fin de estamparlos en la memoria de los fieles; la declamación dramática y la recomendación de emplear símiles y ejemplos para explicar lo abstruso de los dogmas ("hacer las cosas visibles a los ojos"). ${ }^{13} \mathrm{En}$ segundo lugar, los sermones recopilados sirvieron, por un lado, como modelos de dicho género entre 1585 y 1615 y, por otro, como «la fuente principal de sermones para el clero rural durante las primeras décadas del siglo XVII» (Adorno, 1987: 111). Ya Quispe-Agnoli (2006) ha reparado en esta tradición a la hora de explicar algunos aspectos de la obra de Guaman Poma. ${ }^{14}$ En consecuencia, nos parece innegable el manejo que Murúa necesariamente debió de tener sobre esta tradición y sobre las precisiones del Concilio Limense. No solo por la época y la más que probable relación laboral que lo une al cronista indio, sino fundamentalmente por su condición de cura doctrinero.

Cartografiadas estas relaciones y su desarrollo tanto en el ámbito europeo como en el indiano debemos advertir que, debido a los objetivos de nuestro trabajo, solo nos centraremos en analizar aquellos pasajes donde el origen de la ineficiencia administrativa colonial, es decir, la codicia, sea el tema central. El primero de ellos lo hallamos en el capítulo 29; aquí Murúa aprovecha un episodio de la vida de Huayna Cápac para ilustrar y advertir sobre sus peligros. Hualpaya, pariente y hombre de confianza del inca, encarnará dicho pecado:

Bien dijo el apóstol San Pablo, que la codicia era raíz, fuente y oriente de todos los males y pecados, pues ella pervierte y ofusca el entendimiento del hombre, para hacer cosas indebidas y que delante de los ojos del sumo Dios y de los hombres son juzgadas por feas e indignas, sin admitirse escusa. $\mathrm{Y}$ aunque ha habido algunos que se hayan dicho que por ser rey uno, y alcanzar el mando y poderío se podía permitir hiciese traición, yo no hallo razón que justamente permita una cosa tan detestable, como es intentar algo contra su supremo señor de la república, contra su rey y señor natural, en cuya protección y amparo

13 Adorno (1987: 111) nos indica cómo casi punto por punto se siguen Los seis libros de la retórica eclesiástica (1576) de fray Luis de Granada.

$14 \mathrm{Al}$ respecto puede verse el siguiente capítulo: «La Nueva corónica y buen gobierno en la tradición textual hispánica del sermón y la profecía» (Quispe-Agnoli, 2006). 
están sus vasallos, y el que por todos vela ordinariamente y a quien naturalmente se debe fidelidad, amor y reverencia. Y siendo la persona que esto trata más obligada por sangre y parentesco, por beneficios recibidos y, sobre todo, por la confianza que del tutor se hace, como al presente lo vemos en Hualpaya, pariente de Huayna Capac, su tutor y gobernador en todos sus reinos [...]. Este, pues, olvidado de tantas obligaciones como esta dicho y llevado del ciego deseo de ser absoluto señor, y aunque quizás ensoberbecido con el mando, que al presente ejercitaba, o por ventura movido del apetito de ver a un hijo que tenía, puesto en el trono real y grandeza, habiendo algunos años gobernado aquel señorío con fidelidad, atropellando las razones que les impedían hacer lo que hizo, concibió en su pensamiento alzarse y ocupar el reino. (93-94).

Como se aprecia, la estructura homilética es evidente: Murúa cita a San Pablo y a partir de sus palabras extraerá el tema a desarrollar: la codicia. A continuación, define sus características y sus efectos. Nótese además la aparición de un esquema familiar, en este caso, la codicia es madre de todos los vicios. ${ }^{15}$ Esto le permite derivar de ella otro tema: la traición. Nuestro cronista carga las tintas, especialmente, sobre la cometida contra el propio soberano. Finalmente, pasa a la narratio: Hualpaya se erige como la manifestación de estos pecados, incluso en su caso la traición es doble: contra su soberano y contra un miembro de su familia. Si bien Murúa plantea dos escenarios para la causa de su codicia (o bien su deseo de ejercer el mismo el poder o de colocar a su hijo en él) de igual manera esta desemboca en la felonía. En conclusión, el lector debe atender al fin de aquellos que se regodean en el pecado; como nos dice Murúa, el propósito de la historia es enseñar con el ejemplo de los que pasaron. En este caso, Hualpaya, sus cómplices y su descendencia entera terminarán sancionados: ejecutados los primeros, desposeídos y convertidos en esclavos los últimos.

A diferencia del primero, el segundo pasaje va a jugar un rol central en la narrativa histórica. En los capítulos 65 y 66, Murúa cuenta cómo los generales de Atahualpa, Quisquis y Chalco Chima, son derrotados por los conquistadores y Manco Inca. Debido a su colaboración, este último será proclamado soberano; sin embargo, muy pronto las cosas se tuercen y se desata la rebelión. El origen de esta lo halla Murúa en las pecaminosas acciones de Hernando Pizarro.

15 En la tradición cristiana, este lugar suele ser el de la soberbia: «Una lista de ocho pecados tuvo su origen en los monasterios de Egipto en el siglo IV y fue recogida por el monje Evagrius (gula, lujuria, avaricia, codicia, ira, pereza, vanagloria, soberbia). Ella pasó luego a Casiano [...] y a Gregorio Magno quienes la difundieron a toda la Edad Media. Pero Gregorio Magno, si bien sigue a Casiano, instituyó un segundo modelo: el listado septenario. Modificó el esquema octonario colocando un pecado (la soberbia) como raíz de todos los otros [...]. Esto reforzó la imagen de los pecados como una familia y la idea de la comunicación entre ellos» (Bizzarri, 2012: 166). Claramente, Murúa hace eco de esta tradición: conceptúa los pecados como una familia. 
El núcleo explicativo se encuentra tanto en el séptimo como en el octavo párrafo del capítulo 65; así, el séptimo nos da cuenta de las causas de la rebelión de Manco Inca:

ya andaba Manco Ynga con más intención contra los españoles y con ánimo de rebelarse, por los malos tratamientos y molestias que cada día le hacía, casi peores que las que habían recibido de Quisquis y Chalco Chima, porque fue tanta la codicia de los españoles en general y en particular de los capitanes, especial de los hermanos del Marqués, que no había semana ninguna que no le hacían al desventurado amontonar plata y oro como si fueran piedras cogidas del arroyo, y aun con eso no se hartaban dello, porque todo lo jugaban entre sí y lo gastaban, y sobre eso les quitaban las mujeres y las hijas por fuerza, delante de sus ojos, y con estas injurias y agravios se le resfrió a Manco Inga la voluntad y amor que a los españoles tenía (220).

Mientras, el octavo narra, por un lado, los esfuerzos de Francisco Pizarro por aliviar dichas injusticias y, por el otro, el porqué de su infructuosidad: «El Marques tuvo aviso de estas cosas [...], y deseando se evitasen, escribió muy encarecidamente a sus hermanos que tratasen al Manco Ynga bien [...], pero fue su carta de poco provecho [...] porque antes empezaron a hacerlo peor» (220). De la misma manera, el final del capítulo es también plenamente explicativo:

porque así convenía para alcanzar libertad de la opresión en que estaban. Oyendo en todos los lugares del reino este mandado de Manco Ynga, con mucha voluntad se ofrecieron a ello, porque en todas partes corría un lenguaje de los españoles y un trabajo general en los indios, por los malos tratamientos y molestias que les hacían. Todos nacidos de la arrogancia y soberbia en que estaban, que cada día se aumentaba con las riquezas que, lícita o ilícitamente, adquirían entre los indios, sin considerar la estrecha cuenta que dello habían de dar en el tribunal y juicio de Dios, a cuyas orejas llegaban los clamores de los pobres indios (221).

En el pasaje anterior se observa cómo Murúa distingue dos grupos bien diferenciados: los opresores (Hernando Pizarro y sus huestes) y los oprimidos (Manco Inca y su pueblo). Respecto a los primeros se destacan dos características: soberbia y codicia. El primer grupo puede verse circunscrito con claridad hacia la mitad del séptimo párrafo del capítulo 65: aquí se pone el énfasis en la conducta de Hernando Pizarro y sus hermanos hacia el inca y sus nobles. Así, nuestro cronista indica que los conquistadores son «casi peores» (220) que Quisquis y Chalco Chima, ${ }^{16}$

16 Generales de Atahualpa (hermano y enemigo de Huáscar durante la guerra civil en el Tahuantinsuyo), proverbiales por su saña. Sus acciones son resaltadas sobre todo en la crónica de Murúa. 
«por los malos tratamientos y molestias» (220). Todo ello debido a que «fue tanta la codicia de los españoles en general y en particular de los capitanes, especial de los hermanos del Marqués» (220) que, explica el cronista, todas las semanas, sin excepción le hacían juntar oro y plata o, como indica a inicios del primer párrafo del capítulo 66, «lo hacía echar preso sin causa y luego lo soltaba» (221), tras pedirle un cuantioso rescate. Incluso «un día, por sacarle oro y plata, prendió a Manco Ynga y le dio trato de cuerda, y le quitó las mujeres por darle más dolor y pena» (221). Como se aprecia, los opresores son hombres inescrupulosos, injustos y con hambre de oro. Y su jefe, Hernando Pizarro, el más infame de ellos.

Esta serie de abusos produce que el sujeto indígena sea objeto de conmiseración por el lector. Para intensificar este efecto, Murúa adjetiva en varias ocasiones a Manco Inca como el «desventurado» (220) o «el cuitado» (221) y a sus vasallos como «pobres indios» (221). En otras palabras, el cronista nos esboza la siguiente situación: unos súbditos fieles que debido a los abusos han sido llevados al límite de sus fuerzas, siendo así la rebelión el único y lógico corolario. Abusos que hallan su razón en esta hambre de oro que consume a los conquistadores.

En resumen, la soberbia y la brutalidad de los conquistadores, productos de su codicia, serán la báscula que explique el alzamiento de Manco Inca. Dichos defectos, junto con otros, alcanzan en la figura de Hernando Pizarro (y, en menor medida, en sus hermanos y el resto de tropas) su encarnación más pura: el mal trato dado a Manco Inca es el causante de su rebelión y el origen de los incas de Vilcabamba. Estos son el castigo de aquellos pecados: la dimensión aleccionadora es más que clara.

Como observación final, es necesario precisar que esta denuncia constante de la codicia, la cual hemos relacionado con la causa de la ineficiencia administrativa colonial, hace eco, además, de una de las características de la crónica peruana: la marcada influencia del discurso lascasiano a partir de los decenios de 1550 y 1560. Justamente, el hambre de oro y plata fue su principal caballo de batalla. ${ }^{17} \mathrm{~A}$

17 Según Pease (1995), una de las características de la producción cronística del virreinato peruano es el marcado influjo de la prédica lascasiana: «la Brevísima relación y otros tratados escritos contemporáneamente por Bartolomé de Las Casas ejercieron influencia en el Perú» (31). Resta apuntar que esta influencia de las tesis lascasianas en el área andina será más intensa en los decenios de 1550 y 1560. Ahora bien, Valcárcel Martínez (1997) nos señala dicha influencia en algunas crónicas en concreto; así, son claros sus ecos en la Relación de muchas cosas acaescidas en el Perú (1552) de Cristóbal de Molina (el Almagrista) y en la Relación de las antiguas costumbres antiguas de los naturales del Pirú del jesuita anónimo (tal vez Blas Valera). Respecto al primero, se destaca la crítica de dos puntos: el servicio personal indígena y el regicidio de Atahualpa. En cuanto al segundo, Valcárcel Martínez (1997: 143) subraya la misma estrategia lascasiana: contrastar la alabanza del natural manso del indígena con la lujuria y la codicia del conquistador. Sin embargo, es necesario subrayar que la influencia del padre dominico se da en diversos grados. Así, en el Perú, además de los ya mencionados, dicho ascendiente destaca en Cieza de León y en el propio Murúa, pero de manera moderada. Respecto a este último, en el capítulo LXXIV del primer libro, nuestro cronista dedica dos páginas a sintetizar los levantamientos 
continuación, nuestro último apartado está dedicado a analizar uno de los efectos, según el cronista, de la pésima labor de los funcionarios coloniales: la catástrofe demográfica que sufre la población andina.

3.

El cuarto capítulo del tercer libro, intitulado "De las riquezas del reino del Perú", expone con detalle los recursos más abundantes de dicho territorio; realiza una enumeración descendente de acuerdo a la productividad del recurso, por tanto, los metales preciosos van a encabezar la lista: «Este reino del Perú es el más rico de minerales cuanto se sabe, porque casi se puede llamar todo él, en la sierra, una mina de plata y oro» (460). A continuación, prosigue con el control comercial que ejerce en ultramar y finaliza con la abundancia de los ganados («infinitas crías que hay en todo el reino de ganado vacuno y ovejuno y de cerda, que más barato sin comparación se come en el Perú la carne que en España», 462) y la fertilidad del campo («las sementeras de trigo son tantas y tan colmadas, que no se pasa en el Perú hambre [...], se coge infinita azúcar [...], la cogida de vino [...] quien niega que sea de las más ricas del mundo», 463). Nótese que hay un afán hiperbólico en las descripciones de nuestro cronista.

Sin embargo, Murúa rompe la estructura descendente que ha ido construyendo (y por tanto la expectativa del lector) al ubicar el recurso más preciado, según él, en el párrafo final del capítulo:

de los encomenderos producidos por las Leyes Nuevas (1542). De estas, casi página y media son dedicadas a hablar de la labor de Las Casas so pretexto de explicar el origen de las mentadas leyes. La extensión de nuestra cita se justifica por sí misma y por la manera en que se valora hiperbólicamente la labor del dominico: «En este tiempo sucedieron aquellas famosas guerras que se levantaron entre los españoles, originadas de las nuevas ordenanzas que Su Majestad el Emperador nuestro señor hizo para este reino del Pirú y el de Nueva España, a instancia de Don Fr. Bartolomé de las Casas, religioso del Orden de Santo Domingo, obispo de Chiapa. Varón apostólico, acérrimo defensor de la libertad de estos indios, en cuyo amparo y protección se ocupó muchos años, mostrando en España los agravios que de los españoles y encomenderos recibían, la insolencia y tiranía con que eran mandados y hollados, la codicia y ambición con que eran defraudados de sus haciendas, el menosprecio con que eran tratados, como si fueran animales fieros de los bosques, y el gran impedimento que con estas cosas y desafueros ponían los gobernadores y señores de los repartimientos a la promulgación del Santo Evangelio y a la doctrina y enseñanza de estos miserables, como si no fueran hechos a la semejanza de Dios y no fueran comprados con la sangre del cordero inocentísimo. Así hizo un libro donde pone millones de sucesos acontecidos en este reino, nunca vistos ni oídos entre bárbaros, todos enderezados a sacar dinero, oro, plata —y más oro y más plata — sin que pudieran hartar la codicia de los españoles los montes, si oro y plata se tornaran. Defiende con vivas y teológicas razones no ser estos indios tan bárbaros como los hacían, que algunos hubo que se atrevieron a poner en plática no ser verdaderos hombres, que desta suerte los infamaban los que querían apoderarse de sus haciendas y quitarles y privarles del verdadero dominio dellas. Finalmente, mediante su santo celo e infatigable diligencia pudo tanto que se hicieron por el Emperador Nuestro Señor unas ordenanzas nuevas, santísimas y convenientísimas al bien, aumento y conversión destos naturales de este reino» (253-254). 
Una riqueza nos quedaba que referir, y la más principal, de quien penden todas las demás deste reino, y que sin ella todas se han de deshacer y consumir, se va poco a poco disminuyendo. Estos son los indios dél, que por ocultos caminos se menoscaban y cada día parecen menos, y en los llanos, como ya dije, no hay que hacer caudal de ellos. En la Sierra, donde se han conservado mejor, también se van acabando, especialmente en los lugares y pueblos donde van a la labor de las minas. Dios lo remedie como puede, que si ellos faltan, toda la riqueza y abundancia de barras, de tejuelos y de las demás cosas que tengo referidas en este capitulo, se acabarán y fenecerán, pues ellos las crian, conservan cultivan, labran, multiplican, trajinan y sustentan, $y$ de ellos pende el ser y fundamento del reino que, aunque son como la estatua que vio Nabucodonosor, de diferentes metales: oro, plata, cobre, hierro, los pies eran de barro, y en deshaciéndose los pies, cayó y se deshizo la estatua. Si estos pies de barro faltaren, caerá toda la máquina del reino del Perú. Dios lo conserve, amén (464).

Esta cita es valiosa: sintetiza y da forma a una reiterada denuncia diseminada a lo largo de la obra: la aniquilación de la población indígena. Ahora bien, ya no es solo una denuncia que busca en su lector ideal (recordemos que está dedicada al heredero) una respuesta de conmiseración, sino que apela al pragmatismo económico: sin los indios no hay más riquezas ya que ellos sostienen el virreinato, por tanto, debemos ampararlos y propiciar su beneficio. Nótese además el carácter de urgencia con el que escribe nuestro cronista: hace uso de una poderosa imagen y advierte la posibilidad de una ruina total. La maquinaria colonial debe procurar con presteza subsanar dicho problema si no quiere desplomarse como el coloso de Nabucodonosor.

La rareza de este pasaje nos obliga a detenernos y pensar sobre lo que existe detrás de esta compleja argumentación: ¿Murúa, acaso influido por la prédica lascasiana (que, como hemos visto, conoce muy bien y cita), obedece a un motivo filantrópico e intenta articular una estrategia que mueva a las autoridades a remediar la situación del indio si no por caridad cristiana, al menos por conveniencia? ¿O simplemente se trata de un efecto colateral en la búsqueda por favorecer sus propios intereses?; por otro lado, la denuncia del descenso demográfico suscita otra pregunta: ¿parte de una verdadera preocupación o en cierta medida solo hace eco de este tópico? ${ }^{18}$

18 El desmesurado descenso poblacional que sufrió el área peruana hacia finales del s. XVI es reflejado con frecuencia en algunos cronistas como Pedro Cieza de León, Guaman Poma o el mismo Murúa. Espinoza Soriano (1980) señala que se pasó de doce millones de pobladores en 1532 a 1.264.530 en 1572; por su parte, Pease (1995: 33) sitúa dicho descenso entre la formación de los corregimientos (1565) y el establecimiento de las reducciones (1575). Un ejemplo perfecto de la recurrencia y el alcance de dicho tópico lo encontramos en Reginaldo Lizárraga. En su Descripción del Perú, Tucumán, Río de la Plata y Chile (1605) remarca constantemente el fuerte contraste entre la población indígena de los llanos (el litoral) que antes existía y la que actualmente existe: «agora 43 años, poco más o menos, [...] las bocas de los ríos eran poblados de muchos pueblos de indios [...] Todos estos indios se han acabado» (Lizárraga, 1909: 493). Por cada pueblo que pasa repite su letanía, y no solo eso sino que explica la razón, el exceso con la bebida: «la causa de la destruición de tanto indio [...] las borracheras» (493). Así, cuando describe el valle de Chincha, indica: «Cuando los españoles entraron en este reino había en él 30.000 indios tributarios; agora no hay seiscientos» (519) y, algunas líneas después, nos explica: «la disminución han traido las borracheras; son dados mucho á ellas, las 
Optar por una u otra alternativa resultaría demasiado simplista; por el contrario, creemos que existe un poco de todo lo anterior en la solución que propone Murúa. A continuación, bosquejaremos sus circunstancias personales e históricas ya que pueden despejar con mayor o menor efectividad dichas interrogantes y comprender los elementos en juego. En el plano histórico debemos recordar el papel de las reducciones en el virreinato: Francisco de Toledo, al concentrar la población indígena en ellas, buscó regularizar la tributación, la mano de obra y la evangelización.

En este escenario, el progresivo descenso de la población tributaria representó uno de los principales problemas que la administración colonial tuvo que afrontar desde, por lo menos, mediados de la década de 1580. Este fenómeno obedecía a una combinación de dos factores: la profusión de malas cosechas y epidemias que diezmaron a la población nativa durante las dos últimas décadas del siglo XVI y el desarrollo de un "ausentismo antifiscal", práctica que consistía en el abandono de los pueblos altiplánicos sujeto a la mita y la migración y el reasentamiento en corregimientos vallunos libres de mita, estancias de españoles o núcleos urbanos (Morrone, 2019: 53-54).

El mismo autor nos menciona que los casos más espectaculares se dan en la cuenca del Titicaca. Por ejemplo, para el período entre 1573 y 1645, Capachica pasa de unos 1295 pobladores a solo 92, es decir, un descenso del 93\%. Ahora bien, cuando Murúa llega a este poblado (1580) la carga tributaria que portaba, «1295 tributarios sometidos al pago en plata ensayada, piezas de ropa de abasca y hechuras, chuño y pescado» (58), hacía de él un bocado apetecible tanto para la orden mercedaria como para un religioso recién llegado a Indias.

Sin embargo, dicha cuantía va disminuyendo conforme lo hacen los indios y, como muestran los datos, conforme pasan los años. Murúa, que ejerce hasta 1585 , probablemente va a experimentar esto en su propio pecunio. Por ello, posiblemente sostiene que la riqueza del Perú la constituyen los indios y que una muestra de una deficiente administración es el dramático descenso demográfico: «se hallaron en este reino tantos millares de millares de gente, cuando entraron los españoles, de que vemos el día de hoy tan pocos centenares» (331), «estos indios andes cada día van disminuyéndose» (459), «Esta gente [los indios yungas], desde que los españoles entraron en este reino, ha sido cosa notable la disminución en que ha venido, que lugar que tenía diez mil indios, no tiene hoy ciento [...]. Así se ven infinitos pueblos despoblados, sin que haya en ellos más que las paredes caídas que causa lástima y

cuales les abrasan las entrañas [...] desta suerte se han acabado y consumido y los pocos que quedan se consumirán» (520). Una observación final: la asociación de Lizárraga es totalmente peregrina en el contexto peruano pues el descenso demográfico se ligaba casi siempre a enfermedades o al abuso de los españoles. 
compasión, y cada día van menos, de suerte que se entiende que en pocos años se consumirán y acabarán del todo» (452), etc. Y podríamos seguir multiplicando los ejemplos. Sin embargo, veamos cómo este descenso se articula, de manera especular, con la crítica de la administración colonial del momento: o bien respecto a la administración incaica o bien respecto a la toledana.

En cuanto a la primera, cuando Murúa hace la biografía de Tupa Inga Yupangui, relata que fue memorable tanto por sus conquistas como por sus reformas administrativas; al encarecerlas aprovecha nuestro cronista para deslizar su crítica a través de la comparación:

La mucha orden y concierto en que puso este Reino, pues a él se le debe toda la que en él hallaron los españoles, la cual si en lo político y en lo que no contradice a nuestra evangélica religión se hubieran guardado y observara, sin duda que estas amplísimas provincias fueran gobernadas como conviene y los naturales de ellas en grandísimo aumento (315).

Si se tuviera el tino de tal inca no estaría en peligro la riqueza del reino. Asimismo, repite la idea, cuando da una visión de conjunto del Tahuantinsuyo:

No se les puede negar a los Yngas, haber sido en el gobierno político de este tan extendido Reino sumamente avisados, y discretos, gobernando estos indios conforme pide su naturaleza y condición, y acomodando las leyes a las tierras y temples de ellas y a las inclinaciones de los indios. Todos confiesan que si el día de hoy fueran regidos conforme lo fueron de los Yngas, trabajaran más los indios y se vieran mayores efectos de su sudor, y se fueran aumentando en infinito número (339).

En cuanto a la labor de Toledo, en el momento en que existe oportunidad esta es elogiada:

Don Francisco de Toledo [...] dio nuevas órdenes y trazas para el beneficio de los metales por azogue $[\ldots]$ con que añadió a la riqueza del Rey Reino millones de pesos [...]. Finalmente dispuso y ordenó el gobierno del Reino para españoles e indios con tanta prudencia, rectitud y celo, que hasta la fin del mundo durará su memoria en el Perú, mediante las ordenanzas que compuso (466).

En especial, el acento recae sobre la creación de las reducciones: su origen, su finalidad y las mejoras que significaron para la administración colonial. A partir de ello, Murúa cuestiona el actual estado de cosas en el virreinato peruano, pues se están descuidando las instituciones y reglamentaciones impuestas bajo Toledo:

como desease sumamente acertar en el gobierno y regimiento deste reino, que aun en él las desórdenes y pocas justicias no estaban del todo extintas y 
acabadas, y queriendo hacer una visita general de todo el reino de los indios y reducirlos a pueblos en orden y policía cristiana, pues era el único remedio que había para doctrinarlos perfectamente, y que tuviesen noticia de las cosas de Nuestra Santa Fe católica, y se fuesen extirpando de entre ellos los ritos y ceremonias antiguas, mediante la presencia de sus curas y sacerdotes, por cuyo medio se abstendrían de muchos vicios de embriaguez y otros abominables y dañosos, los cuales, por la experiencia se ha visto haber sido cosa convenientísima para la salvación de las almas destos naturales $y$, por el contrario, las reducciones que se han deshecho aumentándose los pueblos mediante las diligencias que hombres de poca conciencia y temor de Dios, cohechados de los indios, han hecho, se ha visto y ve cada día la disminución que hay en el bien espiritual de estas almas, y aun cuantas se mueren sin confesion y sin sacramentos, por esta causa. (270-271)

Finalmente, nuestro cronista sintetiza: «si hoy se guardase lo que él ordenó, mandó y reformó, no habría más que desear y estuviera todo él en suma paz y justicia» (271).

Ahora bien, estas críticas parecen desvanecerse frente a los capítulos quinto y sexto del tercer libro. Únicamente en ellos se habla de manera directa sobre la actualidad y es, solo en ellos, donde nos va a sorprender la actitud elogiosa de Murúa: «en todo el reino, el Rey y sus ministros el principal cuidado con que viven es mirar el bien y conservación de los indios con más diligencia que el de los españoles» (471), pero si es así ¿por qué en páginas anteriores denuncia la desaparición de los pobladores andinos?, ¿acaso Murúa no es consciente de la contradicción en la que cae su discurso?:

No se piense que de parte de los Reyes de España es todo codicia y sacar dineros del Perú, que cierto lo más de sus rentas se emplean en amparar a los indios, que sin duda, fueron venturosos en haber caído en las manos y señorío de los católicos reyes de España [...]. Los tributos que los indios pagan están dispuestos con toda la suavidad posible [...] y en ello se mira su utilidad, de suerte que en todo se han dispuesto sus cosas con la menor carga posible. (471)

De la misma manera, cuando se ocupa de la justicia administrada, Murúa parece describirnos un estado ideal de las cosas. Sin embargo, si leemos con atención, vemos que se hace una distinción entre el sistema y sus funcionarios. El modelo es la perfección encarnada y las intenciones de los altos dignatarios (rey, virrey, etc.), inmejorables; el problema radica en quienes hacen uso del mismo para medrar. Pero, como se ha señalado, ya el cronista ha advertido sobre los peligros de tal pecado (y de otros) en los exempla narrados.

En este sentido, el capítulo 22 del segundo libro es crucial. Aquí Murúa expone la legislación incaica. En el pasaje que citaremos vamos a observar cómo se va a establecer una continuidad entre la administración en el Tahuantinsuyo y la labor toledana. Modelos que destacan la crisis en la que escribe Murúa. A su vez, nos 
permite comprender cómo esta crítica es dirigida a los ejecutantes, no al aparato en sí. Por lo tanto, de aquí que no resulte contradictoria la hiperbólica valoración que se haga del sistema virreinal en los capítulos 5 y 6 del tercer libro. En otras palabras, las bases ya están correctamente sentadas: Toledo puso el cimiento, se falla en la ejecución. Al mismo tiempo, en la crítica de los funcionarios opera una lógica pecado-expiatoria, ${ }^{19}$ se vindica a la codicia como el centro de estos fallos. De aquí que sea subrayada constantemente como un problema hispánico. Veamos el fragmento en cuestión:

Todas estas ordenanzas, que se mandaron guardar con grandísimo rigor, las dio el Ynga puestas con sus ñudos en los cordeles que ya hemos dicho que ellos laman quipos. Dellas sacó hartas el virrey don Francisco de Toledo, que con tanta prudencia y valor gobernó este Reino, cuyas ordenanzas y estatutos el católico rey don Philiphe Segundo mandó se cumpliesen y guardasen [...], las cuales, si el día de hoy se guardase con puntualidad, castigando los transgresores de ellas, sin duda los indios fueran creciendo en número infinito y la justicia y religión cristiana fuera temida y respetada. Pero las personas a cuyo cargo está el cumplimiento de ellas son los primeros a quebrantarlas, y los que habían de tener más cuidado al bien espiritual y temporal de los indios, porque están entre ellos con mando y poder real, son los que disminuyen y hacen mayores vejaciones y molestias, todo por la codicia, raíz y fuente de todos los malos. Dios lo remedie. Amen. (394)

Este arquetipo que propone Murúa puede verse reafirmado no solo en lo que dice sino también en lo que oculta. Expliquémonos, cuando se narra la caída de los incas de Vilcabamba con la ejecución de Túpac Amaru, nuestro cronista configura a Toledo como un instrumento de la justicia divina. ${ }^{20}$ Ahora bien, si analizamos este pasaje, vamos a notar que, aunque Murúa narre lo discutido de la sentencia (los diversos ruegos por la vida del inca, incluso la del mismo Túpac Amaru) y comente la gran lástima de este suceso, no existe una valoración sobre la decisión toledana; solo se repite su negativa rotunda: «cerró los oídos» (297), «resolutamente se lo negó, y

19 Con esta expresión entendemos que para cada acto hay necesariamente una retribución dependiendo del talante de la acción. Esta operación se encuentra en el centro de la comprensión que tiene Murúa sobre la historia; como indica Valcárcel Martínez (1997), entre los cronistas de Indias hay una extendida visión providencialista la cual consiste en pensar que todo lo que acontece en la dimensión individual y social forma parte de un plan divino previamente ya establecido e inmutable. Dicho rasgo es un remanente de la mentalidad colonial y el primero en emplearlo será Colón, que se presenta a sí mismo como un instrumento de la voluntad divina para justificar su conducta en el descubrimiento. Su estrategia sentará un precedente: «después de él lo harían la mayoría de los cronistas, pero cada uno con la mira puesta en la justificación de sus actitudes y sus anhelos personales» (35-36). Las dimensiones de este trabajo no nos permiten extendernos en explicar su funcionamiento al interior de la Historia general del Perú.

${ }^{20}$ En el primer libro se detalla cómo la destrucción del linaje incaico tiene su origen en el asesinato de Fr. Diego. 
cerró la puerta a ruegos y suplicaciones en este caso» (298). Tal vez, la "acusación" más grave que emita sea achacarle inflexibilidad tras el sentido ruego del propio inca:

Rogó muy afectuosamente que no le matase el virrey pues él no le había ofendido ni le era su muerte de ningún provecho, y que lo enviasen a Su Majestad para que allí fuese su yanacona, que quiere decir criado, pero poco aprovechó este ruego, ni movió el corazón duro y obstinado del virrey a lástima ni compasión. (298)

Tras lo desarrollado en este acápite se hace evidente que Murúa busca alejar toda sombra de crítica sobre el proceder de Toledo. Si lo comparamos con las otras crónicas de sus contemporáneos postoledanos esta intención es innegable. Tanto en Garcilaso como en Guaman Poma se critica la decisión del virrey; este último con virulencia (incluso afirma que su desdichado fin es un castigo a su soberbia). Además, en ambas se cuenta algo que elide Murúa: el no tan glorioso fin de Toledo al regresar a España. En las dos crónicas este fallece luego de ser desairado por el rey debido a lo sucedido con Túpac Amaru. El cronista mestizo añade, además, el embargo cautelar de todos sus bienes. Veamos primero la versión de Guaman Poma de Ayala (1615: 461):

y queriendo entrar a bezar las manos de su Magestad al señor y rrey don Phelipe [...], el montero de cámara no le dio lugar ni le dejó entrar ni se le dio lisencia para ello. Con este pesadumbre, se fue a su casa y no comió y se asentó en una cilla. Asentado, se murió [...] y despidió desta vida. Y acabó su uida sentiéndose del dolor de no uer la cara de su rrey y señor. De los males que abía hecho en este rreino, ací al Ynga como a los prencipales yndios y a los conquistadores deste rreyno [...] Y ací la soberbia le mató a don Francisco de Toledo.

Por su parte, Garcilaso de la Vega (2009: 757), con su maestría habitual, lo condensa así:

Con estas imaginaciones de tan grandes méritos, entró a besar la mano al Rey Don Felipe Segundo. La Católica Majestad, que tenía larga y general relación y noticia de todo lo sucedido en aquel Imperio, y en particular de la muerte que dieron al Príncipe Túpac Amaru, y del destierro en que condenaron a sus parientes más cercanos, donde perecieron todos, recibió al Visorrey, no con el aplauso que él esperaba, sino muy en contra. Y en breves palabras le dijo que se fuese a su casa, que Su Majestad no le había enviado al Perú para que matase Reyes, sino que sirviese a Reyes.

Resta decir muy poco; la intención de Murúa es notoria. La labor toledana forma una parte central de su estrategia como para empañarla mencionando su acerbo fin. 


\section{TALIA DIXIT 15 (2020), 77-100}

\section{Conclusión}

Hemos demostrado cómo Murúa critica la labor de los funcionarios coloniales postulando, en primer lugar, una contraparte modélica: el gobierno incaico y el del virrey Toledo; y en segundo, denunciando a la codicia como origen de dicho mal. Esta última echa mano de la tradición ejemplar para advertir sobre las peligrosas consecuencias del abandonarse a tal vicio. Finalmente, el mercedario deplora la desaparición de los naturales e intenta revertir dicha situación bajo un argumento de corte pragmático: la corona debe intervenir pues la verdadera riqueza andina se encuentra en sus pobladores. Este panorama es, para Murúa, otro efecto de la nefasta administración colonial.

CHRISTIAN C. CÁCERES SANDOVAL Universidad Nacional Mayor de San Marcos 


\section{BIBLIOGRAFÍA}

Adorno, R. (1987), “Íconos de la persuasión: la predicación y la política en el Perú colonial", Lexis 2, 109-135.

Adorno, R. (2004), "Estudiosos y censores de la Historia general del Perú (1611-1613) de fray Martín de Murúa", Letras 107-108, 47-72.

Adorno, R. y Boserup, I. (2008), “The Making of Murua's Historia general del Perî’ en The Getty Murua: Essays on the Making of Martin de Murua's "Historia general del Perú», Los Ángeles: Getty Research Institute, pp 7-66.

Aguinagalde, F. B. de (2019), "Un misterio resuelto. El autor de la Historia General del Piru, fray Martín de Murúa (¿1566?-1615), de Eskoriatza” en Vida y obra fray Martín de Murúa, Lima: EY, pp. 194-261.

Alberte, A. (2003), Retórica medieval. Historia de las artes predicatorias, Madrid: Centro de Lingüística Aplicada.

Álvarez-Calderón, A. (2007), "La crónica de fray Martín de Murúa: mentiras y legados de un mercedario vasco en los Andes", Revista Andina 45, 159-86.

Aragüés Aldaz, J. (1993), "El modelo de los dicta et facta memorabilia en la configuración de las colecciones de exempla renacentistas", Humanismo y Pervivencia del Mundo Clásico. Actas del I Simposio Humanismo y Pervivencia del Mundo Clásico I (J.Mª Maestre \& J.Pascual, co.), Cádiz, pp. 267-282.

Aragüés Aldaz, J. (1999), Deus concionator: mundo predicado y retórica del Exemplum en los siglos de oro, Amsterdam: Rodopi.

Battaglia Ricci, L. (2003), "Exemplum e novella", en G. Auzzas (ed.), Letteratura in forma di sermone. I rapporti tra predicazione e letteratura nei secoli XIII-XVI, Firenze, pp. 281-99.

Berlioz, J. (1980), "Le Récit Efficace. L'exemplum au service de la predication (XIIIeXVe siecles)", Mélanges de l'Ecole Française de Rome, 92 (1), 113-46.

Berlioz, J. (1991), "Les recherches en France sur les exempla médiévaux, 1968-1988”, en W. Haug y B. Wachinger (eds.), Exempel und Exempelsammlungen, Tubinga: Niemeyer, pp. 288-317.

Berlioz, J. y Polo De Beaulieu, M.A. (eds.) (1998), Les exempla médiévaux: nouvelles perspectives, Paris: Honoré Champion.

Berlioz, J. y Polo De Beaulieu, M.A. (2000), "La capture du récit. La Disciplina clericalis de Pierre Alphonse dans les recueils d'exempla (XIII'-XIV s.)", Crisol 4, 33-58.

Bizzarri, H. O. (2012), "Sermones y espejos de príncipes castellanos", Anuario de 


\section{TALIA DIXIT 15 (2020), 77-100}

Estudios Medievales 1, 163-81.

Bremond, C., Le Goff, J. \& Schmitt, J.C. (1982), "L' exemplum”, Typologie des Sources du Moyen-Agge Occidental, fasc. 40, Turnhout: Brepols.

Cerezo soler, J. (2018), "Predicación y literatura. La oratoria sagrada en el Siglo de Oro", Miscelánea Comillas 149, 409-20.

Cummins, Th. y Ossio J. (2019), "Introducción” en Vida y obra fray Martín de Murúa, Lima: EY, pp. 16-31.

Delcorno, C. (1989), Exemplum e Letteratura tra Medioevo e Rinascimento, Bologna: Il Mulino.

Espinoza Soriano, W. (1980), "La sociedad andina colonial", en Historia del Perú, Lima: Mejía Baca, pp. 129-337.

Friede, J. (1959), "La Censura Española del Siglo XVI y los libros de Historia de América", Revista de Historia de América 47, 45-94.

García-Bedoya Maguiña, C. (2000), La literatura peruana en el periodo de estabilización colonial (1580-1780), Lima: Fondo Editorial UNMSM.

Garcilaso de la Vega, el Inca (2009), Historia general del Perú, Lima: SCG.

Genette, G. (1989), Palimpsestos. La literatura en segundo grado, Madrid: Taurus.

Genette, G. (2001), Umbrales, México D.F.: Siglo XXI.

Guaman poma de ayala, Felipe (1615), El primer nueva corónica y buen gobierno. GkS 2232, 40, Biblioteca Real, Copenhague, Dinamarca. $1^{\circ}$ de febrero de 2020, 14.00 h. "http://www.kb.dk/permalink/2006/poma/info/es/frontpage.htm."

Harto Trujillo, M. L. (2011), "El exemplum como figura retórica en el Renacimiento", Humanitas 63, 509-26.

Lafond, J. (ed.) (1986), Le modèle à la Renaissance, Paris: Librairie J. Vrin.

Le Goff, J. (1988), The Medieval Imagination, Chicago y Londres: University of Chicago.

Lizárraga, R. de (1909), Descripción breve de toda la tierra del Perú, Tucumán, Río de la Plata y Chile, Edición de M. Serrano y Sanz, Madrid: Biblioteca de Autores Españoles.

López Lamerain, C. (2011), "El III Concilio de Lima y la conformación de una normativa evangelizadora para la provincia eclesiástica del Perú", Intus-Legere Historia 5 (2), 51-68.

Maslakov, G. (1984), "Valerius Maximus and Roman Historiography. A Study of the Exempla Tradition”, $A N R W$ 2, 32, 1, Berlín, New York, 437-496.

Mignolo, W. (1982), "Cartas, crónicas y relaciones del descubrimiento y la conquista", en Historia de la literatura hispanoamericana: Época colonial, Madrid: Cátedra, pp. 57-102. 


\section{TALIA DIXIT 15 (2020), 77-100}

Morrone, A. J. (2019), "Entre altares y escritorios. Liderazgo étnico y poder local en la pluma de tres curas-cronistas del Lago Titicaca (1570-1650)", Memoria Americana. Cuadernos de Etnohistoria 27 (1), 51-86.

Murúa, fray Martín de (2001), Historia general del Perú, Colección Crónicas de América 20, Manuel Ballesteros Gaibrois (ed.), Madrid: Dastin.

Ossio, J. M. (1998), "El original del manuscrito Loyola de Fray Martín de Murúa”, Colonial Latin American Review 7 (2), 271-78.

Pease, F. (1995), Las Crónicas y los Andes, Lima: FCE.

Porras Barrenechea, R. (1986), Los cronistas del Perú (1528-1650) y otros ensayos, Lima: Ediciones del Centenario. Banco de Crédito del Perú.

Quispe-Agnoli, R. (2006), La fe andina en la escritura. Identidad y resistencia en la obra de Guaman Poma de Ayala, Lima: Fondo Editorial UNMSM.

Ricklin, Th. (ed.) (2006), Exempla docent, Paris: Vrin.

Rowe, J. H. (1987), "La mentira literaria en la obra de Martín de Murúa”, en Libro de Homenaje a Aurelio Miró Quesada Sosa, Lima: P.L. Villanueva, vol. II, pp. 753-761.

Tubach, F. C. (1969), Index exemplorum. A handbook of medieval religious tales, Helsinki: Suomalainen Tiedeakatemia.

Valcárcel Martínez, S. (1997), Las crónicas de Indias como expresión y configuración de la mentalidad renacentista, Granada: Diputación Provincial de Granada. 